\title{
Tanzanian malignant lymphomas: WHO classification, presentation, ploidy, proliferation and HIV/EBV association
}

Amos R Mwakigonja ${ }^{1,2^{*}}$, Ephata E Kaaya ${ }^{1,2}$, Thomas Heiden ${ }^{1,3}$, German Wannhoff ${ }^{1}$, Juan Castro ${ }^{4}$, Fatemeh Pak ${ }^{1,5}$, Anna Porwit ${ }^{6}$ Peter Biberfeld ${ }^{1}$

\begin{abstract}
Background: In Tanzania, the International Working Formulation [WF] rather than the WHO Classification is still being used in diagnosing malignant lymphomas (ML) and the biological characterization including the HIV/EBV association is sketchy, thus restraining comparison, prognostication and application of established therapeutic protocols.
\end{abstract}

Methods: Archival, diagnostic ML biopsies $(\mathrm{N}=336)$, available sera $(\mathrm{N}=35)$ screened by ELISA for HIV antibodies and corresponding clinical/histological reports at Muhimbili National Hospital (MNH) in Tanzania between 1996 and 2006 were retrieved and evaluated. A fraction ( $N=174)$ were analyzed by histopathology and immunohistochemistry (IHC). Selected biopsies were characterized by flow-cytometry $(F C)$ for DNA ploidy $(\mathrm{N}=60)$ and some by in-situ hybridization (ISH) for EBV-encoded RNA (EBER, N = 37).

Results: A third $(38.8 \%, 109 / 281)$ of the ML patients with available clinical information had extranodal disease presentation. A total of 158 out of 174 biopsies selected for immunophenotyping were confirmed to be ML which were mostly $(84.8 \%, 134 / 158)$ non-Hodgkin lymphoma (NHL). Most $(83.6 \%, 112 / 134)$ of $\mathrm{NHL}$ were B-cell lymphomas (BCL) (CD20+), of which 50.9\%, (57/112) were diffuse large B-cell (DLBCL). Out of the 158 confirmed MLs, 22 (13.9\%) were T-cell [CD3+] lymphomas (TCL) and 24 (15.2\%) were Hodgkin lymphomas (HL) [CD30+]. Furthermore, out of the $60 \mathrm{FC}$ analyzed ML cases, 27 (M:F ratio 2:1) were DLBCL, a slight majority (55.6\%, 15/27) with activated B-cell like (ABC) and 45\% (12/27) with germinal center B-cell like (GCB) immunophenotype. Overall, $40 \%(24 / 60)$ ML were aneuploid mostly $(63.0 \%, 17 / 27)$ the DLBCL and TCL $(54.5 \%, 6 / 11)$. DNA index (DI) of FCanalyzed ML ranged from 1.103-2.407 (median $=1.51$ ) and most $(75.0 \%)$ aneuploid cases showed high ( $>40 \%)$ cell proliferation by Ki-67 reactivity. The majority $(51.4 \%, 19 / 37)$ of EBER ISH analyzed lymphoma biopsies were positive. Of the serologically tested MLs, 40.0\% (14/35) were HIV positive, mostly with high ( $\geq 40.0 \%)$ Ki-67 reactivity.

Conclusions: According to the 2001 WHO Classification, most subtypes are represented in Tanzanian ML. Extranodal presentation was common among MNH lymphoma patients who also showed high aneuploidy, tumor proliferation (KI-67) and EBER positivity. DLBCL was frequent and phenotype heterogeneity appeared similar to observations in Western countries suggesting applicability of established intervention approaches. HIV was apparently associated with high ML cell proliferation but extended studies are needed to clarify this.

\section{Background}

Malignant lymphomas (ML) represent a spectrum of lymphoid neoplasms with varying prognosis [1]

\footnotetext{
* Correspondence: amwakigonja@muhas.ac.tz
${ }^{1}$ Immunopathology Lab., Cancer Center Karolinska (CCK), Department of

* Correspondence: amwakigonja@muhas.ac.tz
'Immunopathology Lab., Cancer Center Karolinska (CCK), Department of Oncology-Pathology, Karolinska University Hospital Solna/Karolinska Institute, Stockholm, Sweden
}

(c) 2010 Mwakigonja et al; licensee BioMed Central Ltd. This is an Open Access article distributed under the terms of the Creative

including non-Hodgkin lymphoma (NHL), Burkitt lymphoma (BL) and Hodgkin lymphoma (HL). MLs occur worldwide with an increasing incidence both in industrialized countries and Africa [1,2]. Lymphomas represent today an important cause of morbidity and mortality in sub-Saharan Africa, including Tanzania partly due to the HIV and AIDS epidemic [3-5]. 
The classification of NHL has changed over time through the Rappaport Classification developed before lymphoid cells were divided into B-cells and T-cells [6], the International Working Formulation [WF] based on clinical aggressiveness [6], the Kiel Classification (based on histological grade) [7], the Lukes and Collins Classification which separated B-cell and T-cell lymphomas by immunologic techniques [8], the Revised EuropeanAmerican classification of Lymphoid neoplasms [REAL] [4] and most recently, the World Health Organization [WHO] classification $[9,10]$. The later two classifications recognize three major categories, B-cell neoplasms, T/ NK-cell neoplasms and HL [9]. For HL the Rye Classification has been used for many years although, now slightly modified in the WHO/REAL Classification system $[11,12]$. Various countries have tested the applicability and adopted the WHO classification [11,13]. In Tanzania the WF is still used and attempts to apply the WHO classification have so far not been documented. Geographic and racial-ethnic differences in relative frequency of various ML have been reported [5,9]. Such geographic and racial-ethnic differences may influence the adaptation of prognostication as well as therapeutic protocols/algorithms shown to be effective elsewhere. An update and re-appraisal of Tanzanian ML diagnoses and characteristics possibly peculiar to this country is therefore needed.

It is now well documented that ML in HIV and AIDS patients also called AIDS-related lymphomas (ARL) have distinct clinical features including frequent extranodal presentation, which has not been evaluated in Tanzanian ML patients before our current study $[4,14]$.

New insights into the pathogenesis of ML are continuously gained with the development in cytogenetics, molecular biology and immunological techniques [9]. Thus, similar to other cancers, ML may present with genomic instability including specific translocations and numerical chromosomal abnormalities (aneuploidy) [15-17]. Furthermore, the ML association with different viral infections is now well established including the Epstein-Barr virus (EBV) $[4,17,18]$, the human immunodeficiency virus (HIV) [4,17] and recently, Kaposi's sarcoma associated herpes virus/human herpes virus type 8 (KSHV/HHV-8) in primary effusion lymphoma (PEL) and multicentric Castleman's disease (MCD) y. However, the prevalence of such viral associations is still sketchy in sub-Saharan Africa particularly Tanzania and is elucidated in our current study [3-5].

Likewise, the diffuse large B-cell lymphoma (DLBCL) group is now no longer one entity but rather a spectrum of NHL with heterogeneous histopathology, genotype, phenotype and prognosis including germinal center B-cell like (GCB) and activated B-cell-like (ABC) lymphomas $[23,24]$. Thus, the expression of proteins related to germinal centre $B(G C B)$ cell or activated $B$ cells $(\mathrm{ABC})$ and that of apoptosis-regulating proteins have been found to be associated with clinical outcome [25] and in particular Bcl-2 expression is strongly related to poor prognosis [25].

Ki-67 expression by proliferating tumor cells is a well established prognostic marker of malignancies including ML [26,27]. Such prognostic markers are poorly documented in Africa including Tanzania [14] impeding the development of comparable prognostication and adaptation of corresponding therapeutic protocols emphasized by our current studies.

Furthermore, data on clinical presentation and demographic (sex and age) characteristics for Tanzanian ML are scanty [14]. Our recent report on ML tumor proliferation included only mean values for major ML subtypes [14]. Those data are extended by our current long-term study

\section{Methods}

\section{Study area}

The study was conducted in the Histopathology Unit of the Department of Laboratory Services at the Muhimbili National Hospital (MNH) in Dar es Salaam, which is also the teaching hospital for the Muhimbili University of Health and Allied Sciences (MUHAS). MNH is the national referral health care facility in Tanzanian with a bed capacity of over 1000 and receives biopsies from most of the country except the lake zone which has its own manned pathology department.

\section{Clinical presentation}

This was retrieved from clinical records and was determined by physical examination, chest radiography and abdominal ultrasonography during the study period.

\section{Biopsies and HIV serology}

Archival diagnostic biopsy material collected at $\mathrm{MNH}$ between 1996 and 2006 (10 years) was reviewed for histopathology and analyzed by immunohistochemistry (IHC), flow-cytometry (FC) and in-situ hybridization (ISH) at the Immunopathology Lab (Karolinska University Hospital Solna, Stockholm). The fixation and tissue processing protocols remained unchanged during the study period. Biopsies were selected for IHC or FC depending on the basis of representative tissue material per block. Clinical notes and histological reports for all ML biopsies submitted for diagnosis during the same period were also evaluated. The clinical evaluation protocol did not change during the study period. HIV-1 antibody serology (ELISA) was performed at the Microbiology/Immunology department at Muhimbili University of Health and Allied Sciences (MUHAS) as previously described [14,28]. 


\section{Histology}

Primary histological diagnosis on hematoxylin and eosin $(\mathrm{H} \& \mathrm{E})$ stained formalin-fixed paraffin embedded (FFPE) sections was done as previously described, at $\mathrm{MNH}$ according to the International Working Formulation $[4,28]$.

\section{Histopathological re-evaluation}

( $\mathrm{H} \& \mathrm{E}$ and immunoperoxidase assay) of available tissue blocks was done at Karolinska University Hospital Solna independently and by three pathologists (ARM, PB and AP) according to the 2001 WHO classification of lymphoid neoplasms [9]. Inter-observer discrepancies were resolved by all three pathologists sitting together. Out of the $\mathrm{H}$ \& E-evaluated cases biopsies selected based on the histological ML group, tumor:stroma ratio and absent/minimal necrosis, were further evaluated by immunohistology, cytomorphometry, flow-cytometry and in-situ hybridization.

\section{Immunohistochemistry (IHC)}

Immunostaining was done (Immunopathology Lab) by the avidin-biotin complex immunoperoxidase technique as previously described $[4,14,28]$. Briefly, tissue sections were mounted on SuperFrost ${ }^{\oplus}$ slides (Menzel GmbH \& Co KG, Braunschweigh, Germany) deparaffinized, rehydrated and boiled for antigen retrieval at $750 \mathrm{~W}$ by microwave (6 min) in citrate buffer $\mathrm{pH}$ 6. Endogenous peroxidase activity was quenched by incubating the sections in $30 \%$ hydrogen peroxide in distilled water $(30$ $\mathrm{min}$ ) at room temperature (RT) then followed by washing in phosphate-buffered saline (PBS) and incubation with 1:20 normal serum from the species of the secondary antibody and washing (PBS). The sections were incubated overnight at $4^{\circ} \mathrm{C}$ with primary antibody for human antigens including pan-leucocyte CD45 (clone LCA), B-cell CD20 (clone L26), Reed-Sternberg (RS)/ Hodgkin (HC) cells CD30 (clone Ber-H2), the Ki-67 (MIB-1) proliferation marker as well as the polyclonal rabbit CD3 T-cell marker. For DLBCL sub-typing, the immunophenotype of the tumors classified as germinalcenter B-cell like (GCB) or activated B-cell like (ABC) lymphomas was determined using mouse anti-human CD10 (SS2/36), MUM1p (clone MUM1p), BCL-6 (clone PG-B6p) and BCL-2 (clone 124) all obtained from DakoCytomation, (Glostrup, Denmark) were used. The BCL-6/CD10/MuM1p markers were used for phenotypic and the BCL-2/CD10/MuM1p antibodies for prognostic sub-grouping. Thus DLBCLs could be categorized into activated $\mathrm{B}$-cell like $(\mathrm{ABC})$ if they were CD10-/ BCL6+/MUM1p+, CD10-/BCL6- or CD10-/MUM1p+ and germinal center B-cell like (GCB) if they showed CD10+, CD10-/BCL6+/MUM1p- or CD10-/MUM1pimmunophenotypes. Furthermore, DLBCLs were categorized into prognostic group 1 (favourable prognosis) including all BCL-2- cases, BCL-2+/CD10+ and BCL-2+/CD10-/MUM1p- and group 2 (poor prognosis) which included cases with BCL-2+/CD10-/ MUM1p+ reactivity [25]. For primary antibody detection, the sections were incubated (30 min, RT) with anti-species (secondary) antibody and the avidin-biotin complex respectively, and later developed (visualized) with 3,3'-diaminobenzidine (DAB) chromogen (SigmaAldrich, St. Louis MO, USA) as previously described $[4,14,28]$. After PBS washing, the slides were lightly counter-stained with $\mathrm{H} \& \mathrm{E}$, blued in running tap water (30 $\mathrm{min})$, dehydrated in ascending grades of ethanol, cleared in two runs of xylene and mounted with coverslips using Mountex (Histolab Products AB, Göteborg, Sweden).

Negative controls included sections from tissues not expressing the respective antigen as well as substitution of the primary antibody by buffer. Positive controls included tissue sections (lymph nodes and tonsils) with known expression of the antigen under investigation. These controls were included in each experiment.

\section{Microscopic evaluation}

A fluorescence microscope (Olympus BX60, Tokyo, Japan) with a digital camera (Sony DKC-5000, Tokyo, Japan) and various filter cubes was used to document bright field and fluorescence microphotography. Cells were scored on color micrographs in eight adjacent fields $(256 \times 190 \mu \mathrm{m}$ each $)$ of characteristic lesions and the mean count of DAB-positive cells for each primary antibody (marker) was calculated. Strength of CD20 reactivity was subjectively scaled from $1+$ to $4+$ depending on staining intensity, thus intensity $\leq 2+$ was regarded as weak and intensity $>2+$ was regarded as strong). Picture processing and printing was done using Adobe Photoshop 7.0 (Adobe Systems Incorporated, San Jose, USA) and Microsoft-Power Point, 2003 (Microsoft Corporation, Redmond, WA, USA).

\section{Tumor sample selection, enucleation and flow-cytometric analysis (FC)}

FC on extracted lymphoma and tonsillar nuclei was performed as previously described [29]. Selected, nonnecrotic tumour regions containing $\geq 70 \%$ neoplastic tissue in $90 \mu \mathrm{m}$ thick sections were dissected, deparaffinized, rehydrated and digested for 1 hour at $40^{\circ} \mathrm{C}$ with $0.1 \%$ w $/ v$ Sigma protease XXIV (Sigma P8038) [SigmaAldrich, St. Louis, MO, USA] in Tris buffer [0.1 M Tris, $0.07 \mathrm{M} \mathrm{NaCl}$ (pH 7.2) [Merck, Darmstadt, Germany]. The obtained free nuclei in suspension were stained for 30' with 6-diamidino-2-phenylindole (DAPI) solution (10 $\mu \mathrm{M}$ DAPI in $800 \mathrm{mM}$ disodiumhydrogenphosphate) [Sigma D9542, Sigma-Aldrich, St. Louis, MO, USA] and evaluated for DNA content by flow cytometry $\left(\geq 2 \times 10^{4}\right.$ 
nuclei per histogram). For the FC analysis, a PAS II (Particle Analysing System)-cytometer (Partec, Münster, Germany) and a LSRII Flow Cytometer (BD Biosciences, San Jose, CA) were used. The ModFit Program (Verity Software House; Topsham, ME, USA) was used for cell cycle analysis. Ploidy [DNA index (DI)] of diploid and aneuploid ML cell populations was compared to normal tonsil cells as previously described [30,31].

\section{Cytomorphometric evaluation}

Extracted ML and control tonsillar nuclei were stained with DAPI and mounted with Vectashield [Vector Laboratories, Inc. Burlingame, CA, USA] mounting medium for fluorescence microscopy on SuperFrost ${ }^{\oplus}$ slides. The mean size (S) and pleomorphism (P) of nuclei extracted from the tonsils were used as unity and were termed $S_{0}$ and $P_{0}$. Thus relative nuclear size (RNS) was the percentage size in excess of $\mathrm{S}_{0}$ evaluated as $\mathrm{S}_{0}+$ size increase $\leq 25 \%=S 1, S_{0}+$ increase of $26-50 \%=S 2$, $\mathrm{S}_{0}+$ increase of $51-75 \%=\mathrm{S} 3$ and $\mathrm{S}_{0}+$ increase $>75 \%=$ S4. Evaluation of nuclear pleomorphism was $\mathrm{P} 1=$ mild, $\mathrm{P} 2=$ moderate and P3 = high. Mitotic figure counts (MFC) were evaluated on routine $\mathrm{H}$ \& E sections. High power field (HPF) refers to $\times 400$ microscopic magnification.

\section{In-situ hybridization (ISH)}

Epstein-Barr Virus (EBV) infection detection was done by automated ISH as previously described [32] (Pathology Cell analysis Lab, Cancer Center Karolinska) using a fluorescein (FITC)-conjugated oligonucleotide probe to EBV-encoded (EBER) transcripts on FFPE tissue sections optimized for use with Bond Polymer Refine Detection (DS9800) and Anti-Fluorescein Antibody (AR0833) on the Bond-max system (Leica Biosystems Nussloch GmbH, Nussloch, Germany) according to the manufacturer's instructions.

\section{Statistical analysis}

Data was analyzed using Statistical Package for the Social Sciences (SPSS) [SPSS Inc., Chicago Ill]. The Fisher exact test was used for smaller sample sizes. Pvalues of $\leq 0.05$ were considered statistically significant.

\section{Ethical considerations and $\mathrm{MNH}$ guidelines}

These studies were approved by the MUHAS Research Ethics Committee and the Ethical Committee, Karolinska University Hospital Solna (Dnr 01-096).

Upon obtaining individual informed consent and upholding safety, confidentiality and privacy, patients and material at $\mathrm{MNH}$ are also available for education and research since it was established as a University Teaching Hospital by an Act of Parliament. A strictly confidential and coded specimen processing and evaluation was conducted. HIV screening was performed by clinicians upon informed consent in the respective in-/out-patient units.

\section{Results}

\section{$M L$ frequency and general demography}

During the period of study, the histopathology unit at $\mathrm{MNH}$ received approximately 50,000 biopsies including about 7,000 tumors out of which a total of 336 histologically diagnosed $(\mathrm{H} \& \mathrm{E})$ lymphoma cases consecutively collected were evaluated. In 311 of 336 cases the information on patient sex (males 63.3\%, $\mathrm{n}=197 / 311$ and females $36.7 \%, \mathrm{n}=114 / 311$ ) was available. In 281 of 336 cases the age of patients was known, including 107 (38.1\%) children ( $\leq 18$ years), $131(46.6 \%)$ adults (19-54 years) and $43(15.3 \%)$ elderly ( $\geq 55$ years) (Table 1$)$. The overall age ranged from 4 to 91 years with a mean 31 and median of 30 years respectively.

\section{Clinical presentation}

Data on clinical presentation (based on physical examination, radiography, abdominal ultrasonography and endoscopy) was available in 265 patients excluding cases later ruled out as ML after histological and immunohistological review. Majority $64.9 \%,(172 / 265)$ of these ML had nodal and $35.1 \%$ (109) extranodal disease at diagnosis. Extranodal presentation was reported in just over half $(50.9 \%, 54 / 106)$ of childhood ML cases and in $20.9 \%(9 / 43)$ of the elderly, which difference was statistically highly significant $(P=0.00635$, Chi-square Test) [Table 2]. Anatomical sites of extranodal presentation included visceral (12.5\%), bone (10.0\%) and soft tissues (6.4\%) while cutaneous, oral cavity, nasal and ocular in descending order were rare. Furthermore, evaluation of ML anatomical distribution showed that majority $(57.7 \%$ (153/265) had supra-diaphragmatic, $27.5 \%$ (73/265) subdiaphragmatic and $26.8 \%(71 / 265)$ disseminated lymphoma. However, no primary effusion lymphoma (PEL) or primary central nervous system lymphoma (PCNSL), were found in this cohort [Table 3]. Data on clinical

\begin{tabular}{|c|c|c|}
\hline Category & Number of ML cases & Percent \\
\hline Available sex data & $311 / 330$ & 94.2 \\
\hline Female/Male & $114 / 197$ & $36.7 / 63.3$ \\
\hline Available age data (years) & $265 / 330$ & 80.3 \\
\hline Juveniles ( $\leq 18 \mathrm{y}$ ) & 107 & 32.4 \\
\hline Adults (19-54y) & 131 & 39.7 \\
\hline Elderly ( $\geq 55 y$ ) & 43 & 13.0 \\
\hline Mean age & 31.03 & $n a^{*}$ \\
\hline
\end{tabular}

${ }^{*}$ na $=$ not applicable 
Table 2 Anatomical presentation of ML by age-group at MNH from 1996-2006

\begin{tabular}{ccccc}
\hline Age (Years) & \multicolumn{2}{c}{$\begin{array}{c}\text { Anatomical presentation } \\
\text { [No. (\%)] }\end{array}$} & $\begin{array}{c}\text { Total } \\
\text { [No. (\%)] }\end{array}$ & P-value \\
\cline { 2 - 4 } & Nodal & Extra-nodal & & \\
\hline Young ( $\leq 18)$ & $52(33.1)$ & $54(50.0)$ & $\mathbf{1 0 6}(\mathbf{4 0 . 0 )}$ & $\mathbf{0 . 0 0 6 3 5}$ \\
Adults (19-54) & $71(45.2)$ & $45(41.7)$ & $\mathbf{1 1 6 ( 4 3 . 8 )}$ & \\
Elders ( $\geq 55)$ & $34(21.7)$ & $9(8.3)$ & $\mathbf{4 3}(\mathbf{1 6 . 2 )}$ & \\
\hline Total & $\mathbf{1 5 7 ( 5 9 . 2 )}$ & $\mathbf{1 0 8 ( 4 0 . 8 )}$ & $\mathbf{2 6 5 ( 1 0 0 . 0 )}$ & \\
\hline Female & $58(36.9)$ & $45(41.7)$ & $\mathbf{1 0 3 ( 3 8 . 9 )}$ & $\mathbf{0 . 4 6 9 5}$ \\
Male & $99(63.1)$ & $63(58.3)$ & $\mathbf{1 6 2 ( 6 1 . 1 )}$ & \\
\hline Total & $\mathbf{1 5 7 ( 1 0 0 . 0 )}$ & $\mathbf{1 0 8 ( 1 0 0 . 0 )}$ & $\mathbf{2 6 5 ( 1 0 0 . 0 )}$ & \\
\hline
\end{tabular}

NB: 265 is the number of confirmed ML whose clinical data was available

presentation was available in 115 cases morphologically reviewed at the Immunopathology Lab [Table 4]. Differences in distribution of anatomical sites of disease presentation by sex were not statistically significant (p-value 0.4695, Chi-square Test) [Table 2].

\section{Histology and immunohistochemistry (IHC)}

A total of 174 biopsies out of the 336 cases above, were selected and stained by $\mathrm{H} \& \mathrm{E}$ and immunoperoxidase assay (IHC) based on availability of clinical notes, tissue blocks as well as quantity of material per block. After histopathological review and immunophenotyping using a panel LCA, CD20, CD3 and CD30 cell markers, a total of 158/174 were confirmed to be ML and 16 cases (9.2\%) were excluded from further ML sub-classification, DNA ploidy and EBER studies but retained in the general study cohort to account for misdiagnosis. These represented mostly poorly differentiated metastatic carcinomas and sarcomas in lymph nodes as well as neuroendocrine tumors (carcinoids) but also a few cases of chronic inflammation including follicular hyperplasia and tuberculosis. Furthermore, the evaluation revealed 134 (84.8\%) NHL, including 112 (83.6\%) B-cell lymphomas (BCL) [CD20+, CD3-] and 22 (13.7\%) mature T-cell lymphomas (TCL) [CD3+, CD20-] (Table 4). Most of

Table 3 Anatomical site of disease presentation at diagnosis among TZ ML patients at MNH from 1996-2006

\begin{tabular}{ccc}
\hline Anatomical site & Number of $\mathbf{M L}$ cases & Percent \\
\hline Lymph node & 157 & 59.2 \\
Soft tissues & 17 & 6.4 \\
Oral cavity & 8 & 3.0 \\
Skin & 9 & 3.4 \\
Bone & 28 & 10.6 \\
Viscera & 35 & 13.2 \\
Ocular & 4 & 1.5 \\
Nasal & 7 & 2.6 \\
\hline Total & $\mathbf{2 6 5}$ & $\mathbf{1 0 0 . 0}$ \\
\hline
\end{tabular}

NB: 265 is the number of confirmed ML whose clinical data was available the reviewed BCLs, $(50.9 \%, 57 / 112)$ were DLBCL [Figure $1(\mathrm{a}-\mathrm{d})$ ], $20.5 \%(\mathrm{n}=23)$ were BL [Figure $2(\mathrm{a}-\mathrm{d})$ ] and $28.6 \%(n=32)$ were other B-cell lymphomas [Table 4], which included small cell (SCL), lymphoplasmacytic (LP), follicular (FL) and marginal zone B-cell lymphomas (MZBCL) as well as plasmacytoma and oral plasmablastic lymphoma (OPBL). However, primary mediastinal large B-cell lymphoma was not found. TCL included peripheral T-cell lymphoma, extranodal NK/Tcell lymphoma (nasal type), angioimmunoblastic T-cell lymphoma as well as anaplastic large-cell lymphoma. Furthermore, $15.2 \%(\mathrm{n}=24)$ cases were HL $(\mathrm{CD} 30+)$ [Table 4]. As expected, majority $(53.6 \%, \mathrm{n}=15 / 28) \mathrm{B}$ cell lymphomas (BCL) with extranodal presentation were BL cases and most $(80.0 \%, 28 / 35)$ NHL with extranodal presentation were TCL [Table 4]. Of the reviewed HL cases (Table 5), most showed a classical HL (CHL) histopathology) often of the mixed cellularity (MC) subtype [Figure 3(a)]. Furthermore, 6 (25.0\%) cases were CHL nodular sclerosis (NS), 3 (12.5\%) lymphocyte rich (LR) and 2 (8.3\%) were lymphocyte depleted (LD). The non-classical nodular lymphocyte predominant Hodgkin lymphoma (NLPHL) subtype appeared rare $(8.3 \%, 2 / 24)$ [Table 5] in this cohort.

\section{DLBCL sub-typing}

Of the 27 subtyped DLBCL (M:F ratio 1.7:1) cases, 3 (11.1\%) were diagnosed in children and 24 (88.9\%) in adults (Table 6). When sub-grouped for histological presence/absence of follicular structures most $(74.1 \%)$ cases $(\mathrm{n}=20)$ showed completely diffuse architecture and 25.9\% $(\mathrm{n}=7)$ had follicular remnants (Table 6). Using CD10, MUM1p, and BCL-6 markers together, we found that slightly more DLCBL in our series showed an ABC immunophenotype $(55.6 \%, \mathrm{n}=15)$, by comparison to GCB immunophenotype $44.4 \%$ (12) although this was not statistically significant $\left(\mathrm{P}=0.547, \mathrm{Chi}^{2}\right.$ test) [Table 6]. As expected, all DLBCL with follicular remnants were GCB and most (75.0\%) of those completely diffuse were $A B C$. The DLBCL immunophenotypes were associated with varying strength of $\mathrm{CD} 20$ reactivity and majority $(57.1 \%, 12 / 21)$ of cases with strong reactivity were GCB $(\mathrm{p}=0.02)$. Thus most $(70.4 \%, 19 / 27)$ DLBCL examined were group 1 and $29.6 \%(8 / 27)$ were group 2 according to BCL-2/CD10/MuM1p sub-grouping (Table 6). In the present cohort, DLBCL subtype was not significantly correlated to age-group, HIV serostatus, tumor proliferation (Ki-67+) or DNA index/ploidy status which however, could depend on the small sample size.

\section{Cell proliferation by Ki- 67 immunohistochemistry and flow-cytometry (FC)}

As expected, the highest (mean $=91.5 \%$, range $75-98 \%$ ) reactivity was found among $\mathrm{BL}$ cases [Figure 2(c)] 
Table 4 Anatomical presentation of ML at diagnosis (MNH) by their reviewed histological subtypes (1996 -2006)

\begin{tabular}{|c|c|c|c|c|c|c|}
\hline \multirow[t]{2}{*}{$\begin{array}{c}\text { Reviewed histological } \\
\text { diagnosis }\end{array}$} & \multicolumn{2}{|c|}{$\begin{array}{c}\text { Anatomical Site } \\
{[\text { No. (\%)] }}\end{array}$} & \multirow{2}{*}{$\begin{array}{l}\text { Reviewed cases with available } \\
\text { clinical data } \\
{[\text { No. }(\%)]}\end{array}$} & \multirow{2}{*}{$\begin{array}{c}\text { Clinical data } \\
\text { unrecorded } \\
\text { [No. (\%)] }\end{array}$} & \multirow{2}{*}{$\begin{array}{c}\begin{array}{c}\text { Sub- } \\
\text { totals }\end{array} \\
{[\text { No. }(\%)]}\end{array}$} & \multirow{2}{*}{$\begin{array}{c}\text { Total reviewed } \\
\text { ML } \\
{[\text { No. }(\%)]}\end{array}$} \\
\hline & Nodal & Extranodal & & & & \\
\hline$D L B C L$ & $\begin{array}{c}35 \\
(64.8)\end{array}$ & $7(25.0)$ & 42 & 15 & $57(50.9)$ & \\
\hline$B L$ & $2(3.7)$ & 15 (53.6) & 17 & 6 & $23(20.5)$ & \\
\hline Other $B C L^{*}$ & $\begin{array}{c}17 \\
(31.5)\end{array}$ & $6(21.4)$ & 23 & 9 & $32(28.6)$ & \\
\hline Total BCL & $\begin{array}{c}54 \\
(83.1)\end{array}$ & $28(80.0)$ & 82 & 30 & $\begin{array}{c}112 \\
(83.6)\end{array}$ & 112 (83.6) \\
\hline TCL & $\begin{array}{c}11 \\
(16.9)\end{array}$ & $7(20.0)$ & 18 & 4 & & $22(13.7)$ \\
\hline TOTAL NHL & $\begin{array}{c}65 \\
(65.0)\end{array}$ & $35(35.0)$ & 100 & 34 & & $134(84.8)$ \\
\hline $\mathrm{HL}$ & $\begin{array}{c}10 \\
(66.7)\end{array}$ & $5(33.3)$ & 15 & 9 & & $24(15.2)$ \\
\hline $\begin{array}{l}\text { TOTAL REVIEWED ML } \\
\text { [No. (\%)] }\end{array}$ & $\begin{array}{c}75 \\
(65.2)\end{array}$ & $40(34.8)$ & $115(72.8)$ & $43(27.2)$ & & $158(100.0)$ \\
\hline
\end{tabular}

${ }^{*} \mathrm{BCL}=\mathrm{B}$-cell lymphomas

followed by DLBCL (mean 42.4\%, median 40.0\%, range $10-90 \%$, SD 23.5) and closely by TCL (mean $42.3 \%$, median $50.0 \%$, range $10-80 \%$, SD 24.2 ) and lowest for HL [Figure 3(b)]. Furthermore, possible associations between Ki-67 index, sex, age or clinical presentation of ML cases as well as with that of different DLBCL subtypes, were not statistically significant. However, as expected, most $(88.9 \%, 8 / 9)$ aneuploid ML cases showed high tumor proliferation rates ( $>40 \% \mathrm{Ki}-67$ reactivity) while only $11.1 \%$ of diploid ML had high tumor proliferation which difference appeared to be statistically significant (p-value 0.04, Fisher's Exact Test). FC S-phase
Fraction (SPF) showed a mean for all ML of $19.6 \%$ (median $=16.5 \%)$ ranging from $3.8-39.7 \%$. Comparison between Ki-67 index and SPF showed a significant correlation $\left(R^{2}=0.55\right)$ between the mean SPF and Ki-67 reactivity.

\section{Epstein-Barr virus (EBV)}

EBER in-situ hybridization (ISH) [Figures 2(d) \&3(c)] was evaluated on $37 \mathrm{ML}$ cases of which the majority (51.4\%) were positive (19/37). Most (68.4\%) of the EBER + cases were found in the adult age-group (13/19) followed by juveniles $(26.3 \%, 5 / 19)$ and rare in the

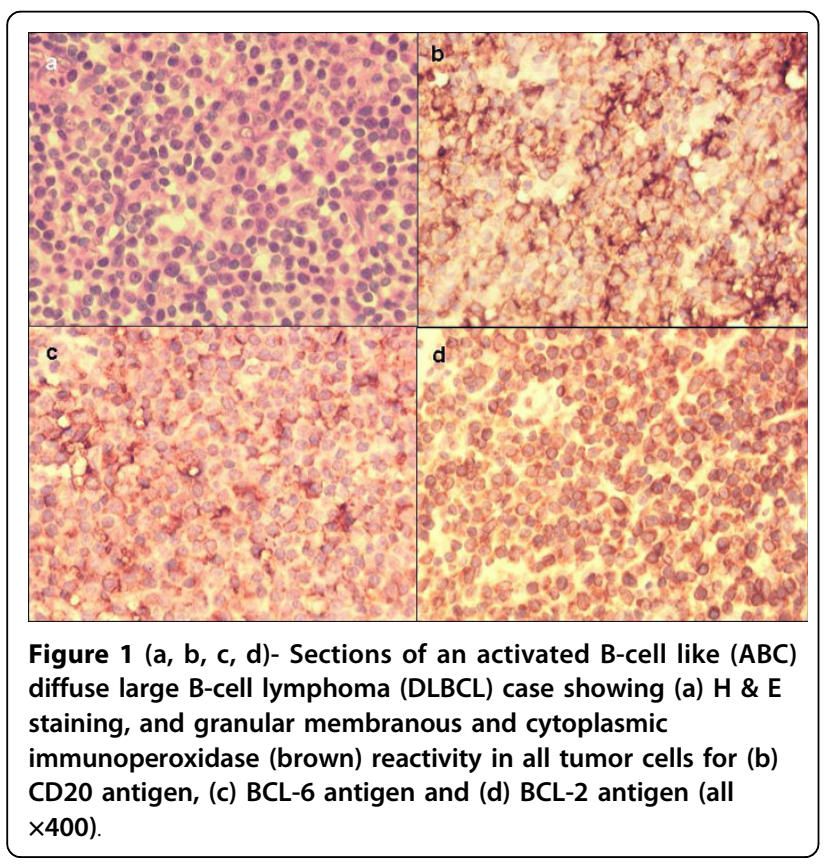

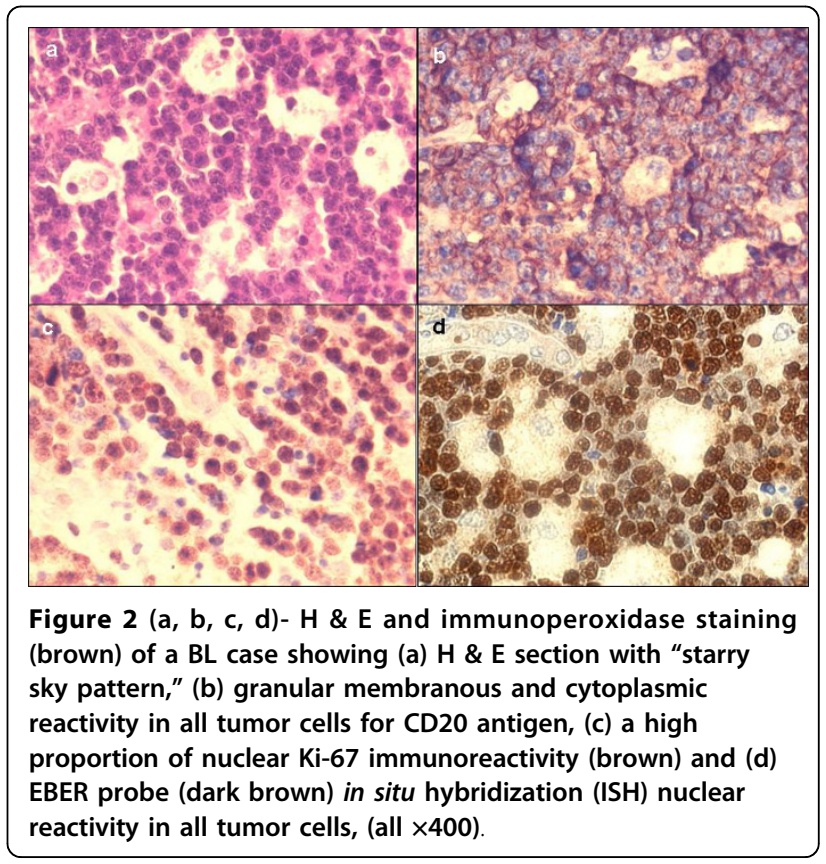


Table 5 Histological subtypes of reviewed Hodgkin lymphoma (HL) cases from MNH between 1996 and 2006

\begin{tabular}{ccc}
\hline Histological diagnosis & Number & Percent \\
\hline Classical HL (CHL) & & \\
Mixed cellularity (MC) & 11 & 45.8 \\
Nodular sclerosing (NS) & 6 & 25.0 \\
Lymphocyte rich (LR) & 3 & 12.5 \\
Lymphocyte depleted (LD) & 2 & 8.3 \\
Non-classical HL & & \\
Nodular lymphocyte predominant (NLPHL) & 2 & 8.3 \\
\hline Total HL & $\mathbf{2 4}$ & $\mathbf{1 0 0 . 0}$ \\
\hline
\end{tabular}

group of elderly patients, which difference was statistically significant $(\mathrm{p}=0.048)$. EBER reactivity was not correlated with either of the DLBCL immunohistological subtypes, $\mathrm{p}=0.87$ (not statistically significant, Chisquare test). Furthermore, EBER positivity correlation with sex, clinical presentation, tumor proliferation (Ki-67) and DNA index (DI) was also not statistically significant.

\section{Cytomorphometry results}

DAPI-stained nuclei from 60 selected out of the 158 evaluated ML as well as from 3 tonsils were examined microscopically for changes in nuclear size, shape pleomorphism and cellularity (Figure 4) and as expected the highest nuclear size (S4) was most frequently seen in HL cases while a difference of nuclear pleomorphism (NP) and for DI between different ML groups did not appear to be statistically significant. Obviously,

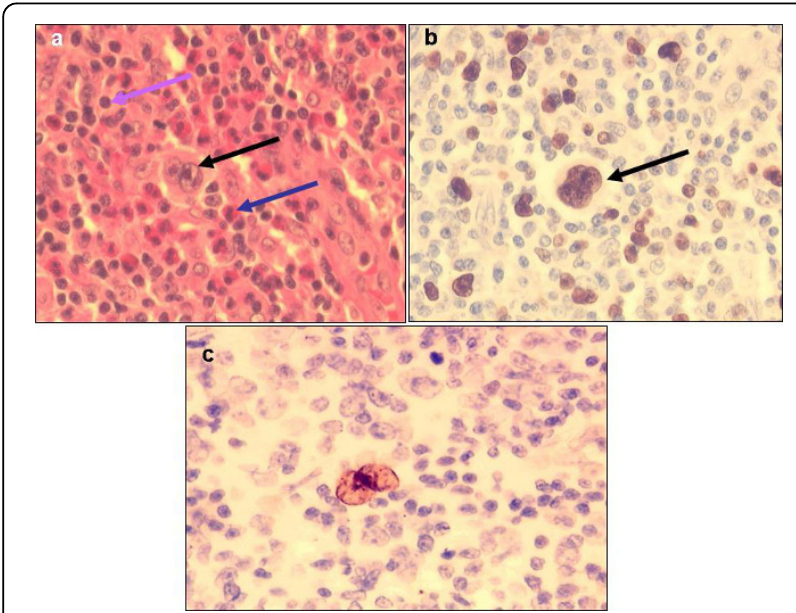

Figure 3 ( $a, b, c$ ) - HL histologic sections: (a) H \& E staining of a classical HL mixed cellularity (MC) case showing Reed-

Sternberg (RS) cells (black arrow), eosinophils (blue arrow) and lymphocytes (purple arrow), (b) nuclear Ki-67

immunoperoxidase reactivity (brown) in an RS cell, and (c) an EBER positive (brown) RS cell (all $\times 400$ ).

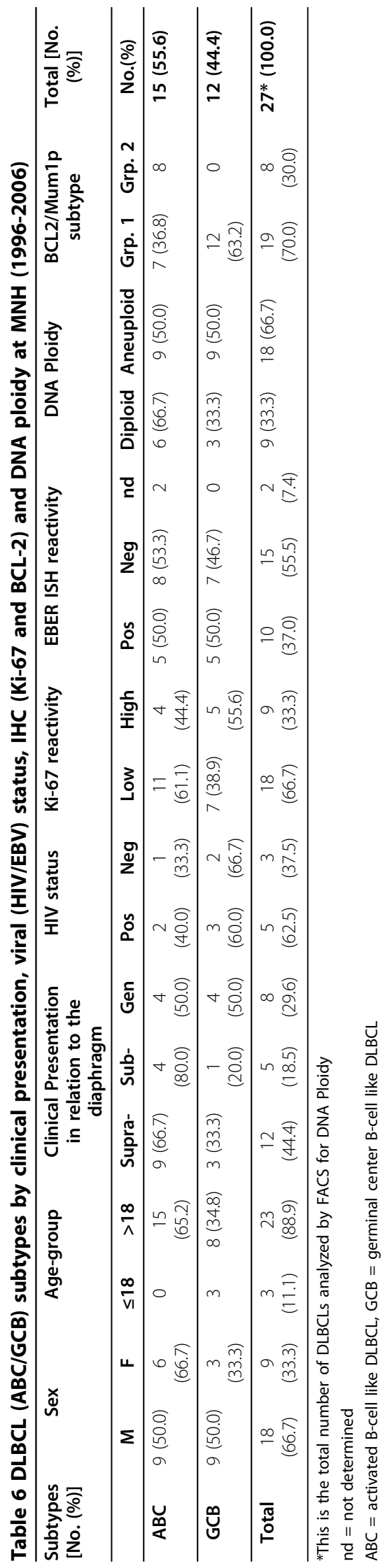




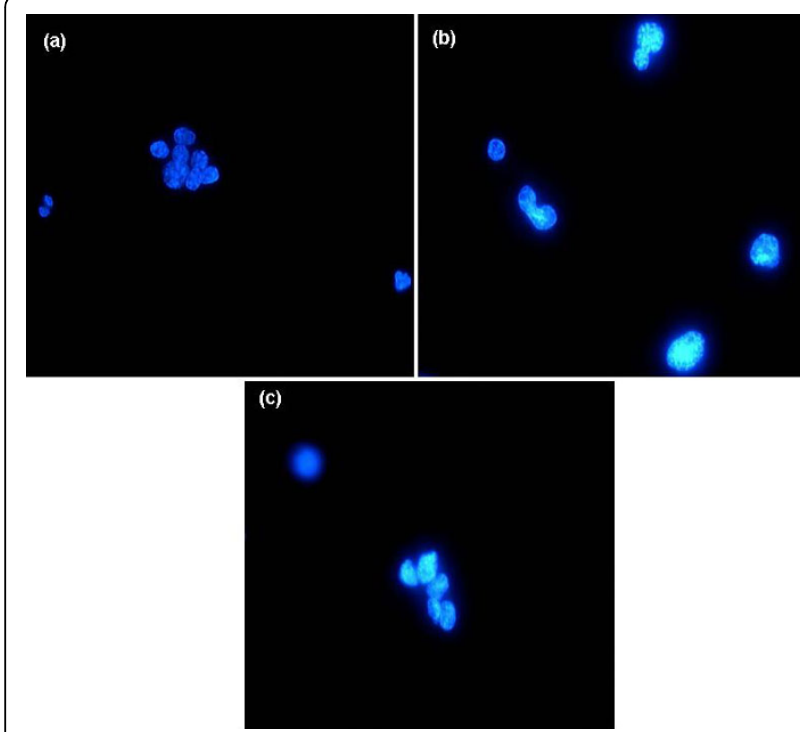

Figure $4(a, b, c)$ - DAPI stained nuclei from a (a) normal paraffinized tonsil showing relative monomorphism and from DLBCLs showing pleomorphism (b \& c) and mitoses (b).

cellularity (number of nuclei/hpf) appeared significantly higher in BL followed by DLBCL, TCL and least in HL and appeared to correlate well with the median $\mathrm{Ki}-67$ immunoreactivity.

\section{Flow cytometric (FC) results}

The nuclei extracted from the 60 selected cases evaluated by cytomorphometry above [including 27 DLBCL, $7 \mathrm{BL}, 4$ other B-cell lymphomas (BCL), 11 TCL and 11 $\mathrm{HL}$ ] as well as those from three normal tonsils were analyzed for DNA index (DI) and tumor proliferation [S-Phase fraction (SPF)]. Microdissection and/or lasercapture microscopy (LCM) could not be done for HL cases in the current study due to logistical limitations. Thus, the HL ploidy results presented hereinafter are expected to serve as a proxy for HL cases at MNH. All the tonsillar controls were euploid or diploid $(\mathrm{DI}=1$ ) [Figure 5 (a)] but also some DLBCL [Figure 5(b)] and other BCL (including BL) as well as some TCL and most HL. Overall, 40\% (24/60) of the selected ML cases showed DNA aneuploidy and the highest $(63.0 \%, 17 / 27)$ frequency was seen in the DLBCL group followed by TCL $(54.5 \%, 6 / 11)$ while aneuploidy was rare $(14.3 \%, 1 /$ $7)$ in BL cases respectively, which differences were not statistically significant (p-value $0.062, \mathrm{Chi}^{2}$ test). Aneuploid DNA indices (DI) for tested ML biopsies ranged from 1.103 to 2.407 (mean $=1.65$, median $=1.51, \mathrm{SD}=$ $0.445)$. About $37.5 \%(\mathrm{n}=8)$ aneuploid cases were hyperdiploid ( $>$ DI < 1.3) mostly DLBCL $(77.7 \%$, 7/8) [Figure $5(\mathrm{c})$ ] but also one TCL (12.5\%) [Figure 5(d)] ( $\mathrm{p}=0.369$, not statistically significant). Furthermore, only $12.5 \%(\mathrm{n}=3 / 24)$ of aneuploid ML cases showed triploidy $(1.3 \geq \mathrm{DI}<1.7)$ including two DLBCL [Figure $6(\mathrm{a})$ ] and one BL whereas $50.0 \%$ were tetraploid/multiploid (DI $\geq 1.7$ ) [12/24] including DLBCL $(58.3 \%, \mathrm{n}=7$ ) [Figure 6(b)] and TCL $(41.7 \%, \mathrm{n}=5)$ [Figure 6(c)]. Thus tetraploidy appeared to be more $(83.3 \%, 5 / 6)$ frequent among TCL cases compared to DLBCL (47.1\%, 7/17) which difference was not statistically significant ( $\mathrm{p}=0.161$, Fisher Exact Test).

\section{ML association with HIV infection (serology)}

HIV screening was possible in only $22.2 \%(35 / 158)$ of the histologically reviewed ML cases of which $40.0 \%$ (14/35) were seropositive. Apparently, most (85.7\%, 12/ 14) of the positive cases were seen in the younger adults (age 18-54). Furthermore, most $(77.8 \%, 7 / 9)$ of the HIV seroreactive ML stained for Ki-67 showed high ( $\geq 40.0 \%)$ reactivity, which difference was statistically significant ( $p=0.021$, Fisher's Exact Test) [Figure 6(d)]. HIV association with sex, clinical presentation (disease extent and anatomic location), EBV infection (EBER+ ISH), and DNA index (ploidy) of ML cases appeared not statistically significant which could be due to small samples.

\section{Discussion}

The ML demographics found in the studied, extended 10 year cohort are generally consistent with age and sex distribution of Tanzanian lymphomas discussed in our previous reports $[4,14]$. The finding that about one-third of the ML had extranodal presentation at diagnosis is of therapeutic importance and remarkably concordant with the 30-40\% extranodal presentation observed among DLBCLs in Wurzburg, Germany [33] but not previously documented in Tanzania and in contrast to the frequency reported in Japan where extra-nodal presentation was higher $(83.3 \%)$ in the young than $(60.0 \%)$ in the older age-group [34]. Concordant with our findings in juvenile ML cases [34], nodal versus extranodal presentation is reportedly an important factor for determination of ML prognosis and pathogenicity related to genotypic and phenotypic differences in the two clinical groups which however is not well established [35]. Thus it seems that nodal and extranodal DLBCL, as well as DLBCL from different primary sites, are heterogeneous with regard to different biologic characteristics and prognostic implications [35]. Corresponding to other studies [36,37] we also found that TCL were more often associated with extranodal presentation particularly cutaneous and nasal compared to other ML subtypes [36,37].

Lymphoma classification remains a challenge particularly to resource-limited countries in Africa, where methods complementary to routine histology such as 

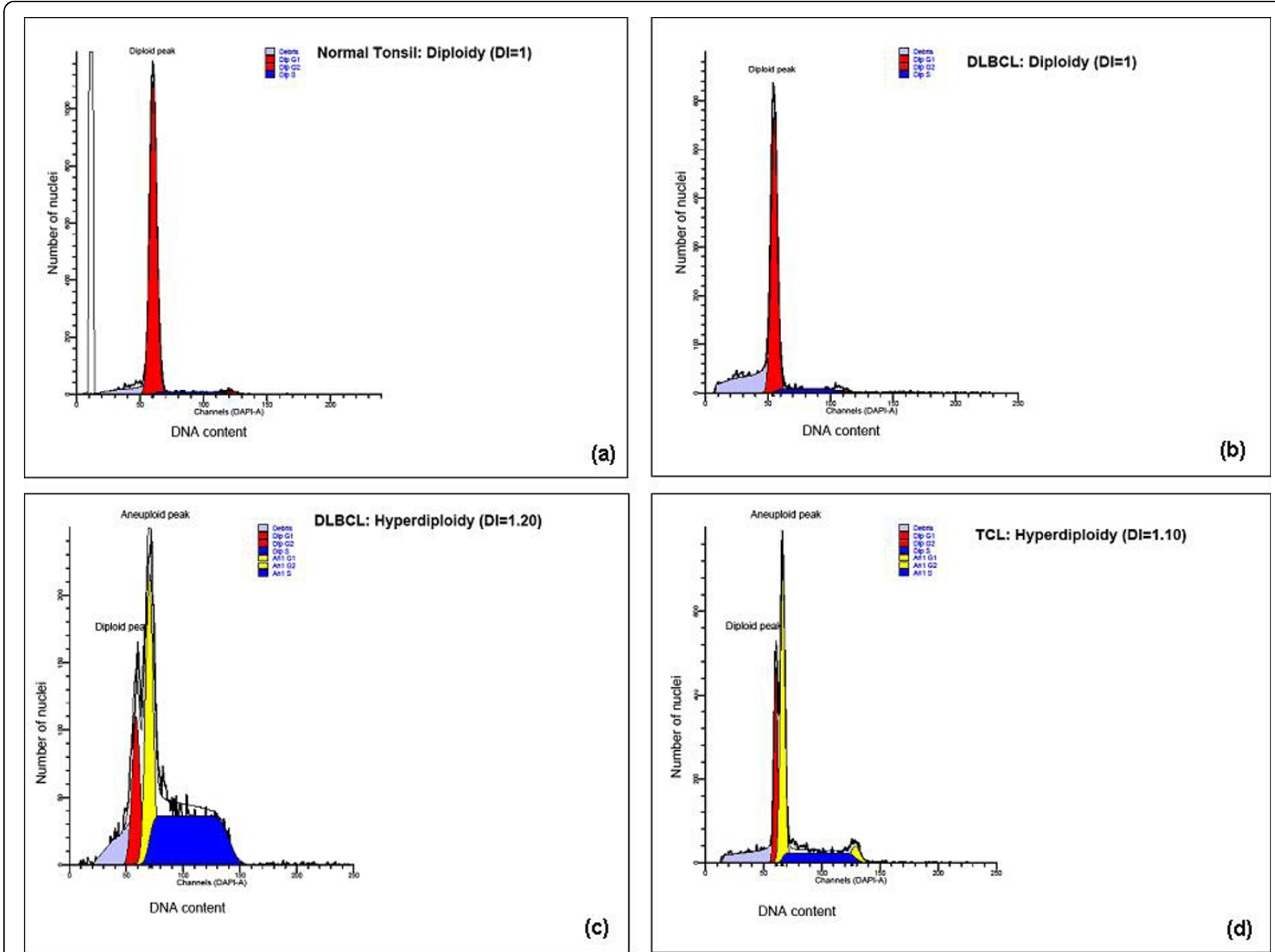

Figure 5 (a, b, c, d)- DNA histograms of a diploid normal tonsil control (a), diploid (b) and hyperdiploid (c) DLBCLs as well as a hyperdiploid TCL (d).

IHC, FACS, PCR and cytogenetics are mostly lacking. This is also the reason why the WHO classification has been difficult to implement in Tanzania. As realized from the present study combined immunophenotyping and $\mathrm{H} \& \mathrm{E}$ staining, clearly improved diagnostic specificity and should be implemented routinely. Thus the diagnosis of TCL by IHC in the current ML cohort to our knowledge is novel in Tanzania. Furthermore, the dominance of B-cell lymphomas, mostly DLBCL also reported in our previous study [14], and the proportions of BL, TCL and HL at MNH appear similar to other studies [9] suggesting the applicability of the WHO classification for Tanzanian ML.

The sub-phenotyping of African DLBCL by IHC using CD10, MUM1p and BCL- 6 as well as BCL-2 cell markers in the present study has not our knowledge, been reported before in Tanzania and Africa. Thus, our findings indicate that previously established DLBCL subphenotypes also exist in Tanzania/Africa, which should allow the application of the same prognostication criteria and therapeutic protocols as those in developed countries. The apparently higher frequency of the $\mathrm{ABC}$ than GCB lymphomas, in the current MNH cohort appear to be concordant with several DLBCL studies from North America and Western Europe [23,25] although our sample size was small. However, this concordance may support the notion of pathogenic and biological similarity between Caucasian and African DLBCL heterogeneity. Our finding of architectural (histological) differences between diffuse DLBCL and those with follicular remnants suggests also the existence of DLBCL which may develop from nodal follicular lymphoma (FL) [38].

Furthermore, the application of the WHO classification of Tanzanian HL in the current study is novel including the reporting of classical (CHL) and the nonclassical nodular lymphocyte predominant (NLPHL) cases. However, our HL findings of more frequent mixed cellularity (MC) than nodular sclerosing (NS) among cases with CHL, were not in agreement with 


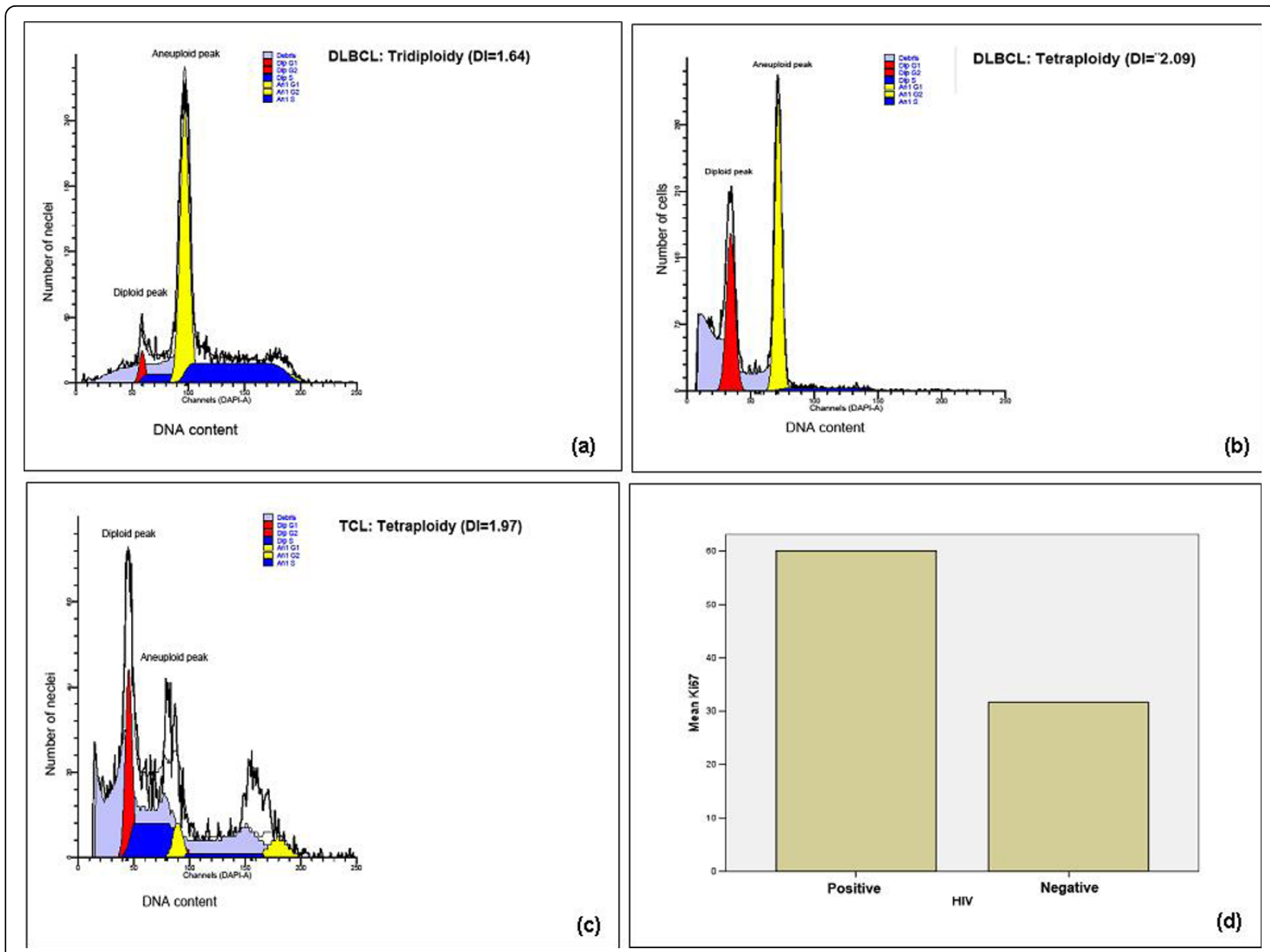

Figure 6 ( $a, b, c, d)$ - DNA histograms of triploid (a) and tetraploid (b) Tanzanian DLBCLs, a tetraploid TCL (c), as well as a histogram of median Ki-67 reactivity (proliferation) and HIV serostatus in Tanzanian ML patients (d).

reports from other countries were NS is reportedly more common $[39,40]$ although other reports seem to concur with our current findings [11,41,42]. The reason for this discrepancy are not clear but the may possibly include the role of HIV infection in altering the epidemiology, pathogenesis and natural history of HL $[41,42]$ considering that Tanzania is within the epicenter of the HIV and AIDS pandemic. However, these results could also depend on the sample size.

The $40 \%$ rate of aneuploidy found among the Tanzanian ML patients indicates a relatively high prevalence of genomic instability (chromosomal aberrations) and is in general in agreement with previous reports from Western countries $[43,44]$ but higher than that observed among NHL in a Swedish report [16]. High DNA indices (triploidy, tetraploidy and multiploidy) were also found in our current study as well as a high mean DI comparable to other reports $[16,45]$, which appears to correlate with biological aggressiveness and poor prognosis. The high DI (tetra-/multi-ploidy) and proportion of aneuploidy found most frequently among the current DLBCL cases is concordant with previous reports [45]. However, the lack of aneuploidy among our HL cases is in contrast to other reports [46] and could probably be due to the fact that microdissection/LCM for the neoplastic Reed-Sternberg cells (RSC) and/or Hodgkin cells (HC) was not done in our current study due to resource limitations as well as difficulty in suspending intact RSC known to be aneuploid. The strong correlation between aneuploidy and tumor proliferation (Ki-67) found in our study was expected as previously reported by others [47] and is indicative of a biological high tumor grade. There was no association between aneuploidy and HIV infection in our cohort but previous reports suggested higher proliferation and lower DI among HIV-associated lymphomas [44]. However, these reports are scanty, and further documentation is needed [48]. Furthermore, the finding that EBER positivity in our cohort, did not appear to be clearly associated with high tumor proliferation (Ki-67) could partly be due to the small sample 
size. Furthermore, the high frequency of EBER+ ML in our ISH-tested biopsies indicates a significant association of lymphomas with EBER positivity at MNH particularly in the adult age-group (68.4\%) and is consistent with our previous report [4], in which we also showed co-expression (31.8\%) of tumoral EBV-encoded RNA (EBER) and HHV-8 DNA (PCR) but not ML cell HHV-8 latency-associated nuclear antigen (LANA) association [4].

The finding that increased tumor proliferation in our current cohort appeared correlated to HIV infection, is concordant with previous reports [44] and supports the notion of viral-associated/driven tumor proliferation as a biological role in the oncogenesis of HIV-related malignancies similar to that reported for HHV-8 and Kaposi's sarcoma [28].

\section{Conclusions}

The WHO Classification can apparently be applied for the diagnosis of lymphomas at MNH in Tanzania. Extranodal presentation of ML was frequent particularly for TCL. DLBCL subtype phenotype heterogeneity and frequency was similar to that observed in Western countries suggesting applicability of similar, diagnostic, prognostic and therapeutic approaches. Lymphomas at MNH appear to have frequent aneuploidy and EBER positivity as well as high DNA indices and tumor proliferation (Ki-67). HIV is apparently associated with increased ML cell proliferation but extended studies are needed to confirm this.

\footnotetext{
Acknowledgements

We are greatly indebted to the MNH patients who provided their biopsies and sera as well as to the department of surgery for submitting them, and to Onjection Byobangamba and Jafari Sufi (MUHAS) for technical assistance. Constructive criticism from Dr. Esmeralda Castanõz-Velèz and Prof. Birger Christensson is also appreciated. Financial Support was provided by the Swedish International Development Agency (Sida), Department of Research Cooperation (SAREC), Cancer Fonden and KI Fonden.
}

\section{Author details \\ ${ }^{1}$ Immunopathology Lab., Cancer Center Karolinska (CCK), Department of Oncology-Pathology, Karolinska University Hospital Solna/Karolinska Institute, Stockholm, Sweden. '2Department of Pathology, Muhimbili University of Health and Allied Sciences (MUHAS), Dar es Salaam, Tanzania. ${ }^{3}$ Pediatric Clinic specialized on Oncology and Hematology, Otto-Heubner-Center for Pediatrics, Charité Campus Virchow-Klinikum, Berlin, Germany. ${ }^{4}$ Cancer Center Karolinska (CCK) Core Facility, Department of Oncology-Pathology, Karolinska University Hospital Solna/Karolinska Institute, Stockholm, Sweden. ${ }^{5}$ Department of Immunology, Semnan Medical University, Semnan, Iran. ${ }^{6}$ Department of Pathology, Radiumhemmet, Karolinska University Hospital Solna, Stockholm, Sweden.}

\section{Authors' contributions}

ARM, PB, EK and AP designed research. ARM collected data. ARM, TH, JC, GW and FP performed research. ARM, PB, AP, TH, JC, GW, EK analyzed and interpreted data. ARM performed statistical analysis and wrote the manuscript. PB, AP, TH and EK corrected manuscript. PB contributed vital reagents and analytical tools. All authors read and approved the final manuscript.

\section{Competing interests}

The authors declare that they have no competing interests.

Received: 4 July 2009 Accepted: 1 July 2010 Published: 1 July 2010

\section{References}

1. Omoti CE, Halim NK: Adult lymphomas in Edo state, Niger Delta region of Nigeria-clinicopathological profile of 205 cases. Clin Lab Haematol 2005, 27(5):302-306.

2. Baris D, Zahm SH: Epidemiology of lymphomas. Current opinion in oncology 2000, 12(5):383-394.

3. Chokunonga E, Levy LM, Bassett MT, Borok MZ, Mauchaza BG, Chirenje MZ, Parkin DM: Aids and cancer in Africa: the evolving epidemic in Zimbabwe. AIDS (London, England) 1999, 13(18):2583-2588.

4. Kaaya E, Castanos-Velez E, Ekman M, Mwakigonja A, Carneiro P, Lema L, Kitinya J, Linde A, Biberfeld P: AIDS and non AIDS-related malignant lymphoma in Tanzania. African health sciences 2006, 6(2):68-74.

5. Parkin DM, Pisani P, Ferlay J: Global cancer statistics. CA: a cancer journal for clinicians 1999, 49(1):33-64, 31

6. Christensson B, Tribukait B, Linder IL, Ullman B, Biberfeld P: Cell proliferation and DNA content in non-Hodgkin's lymphoma. Flow cytometry in relation to lymphoma classification. Cancer 1986, 58(6):1295-1304.

7. Lindemalm C, Biberfeld P, Bjorkholm M, Holm G, Johansson B, Mellstedt $H$, Nilsson B, Ost A: Immunodeficiency and prognosis in patients with nonHodgkin's lymphomas. Acta radiologica 1985, 24(2):159-165.

8. Higgins RA, Blankenship JE, Kinney MC: Application of immunohistochemistry in the diagnosis of non-Hodgkin and Hodgkin lymphoma. Archives of pathology \& laboratory medicine 2008, 132(3):441-461.

9. Ohshima K, Suzumiya J, Kikuchi M: The World Health Organization classification of malignant lymphoma: incidence and clinical prognosis in HTLV-1-endemic area of Fukuoka. Pathol Int 2002, 52(1):1-12.

10. Hasserjian RP, Ott G, Elenitoba-Johnson KS, Balague-Ponz O, de Jong D, de Leval L: Commentary on the WHO classification of tumors of lymphoid tissues (2008): "Gray zone" lymphomas overlapping with Burkitt lymphoma or classical Hodgkin lymphoma. Journal of hematopathology 2009.

11. Chan JK: The new World Health Organization classification of lymphomas: the past, the present and the future. Hematological oncology 2001, 19(4):129-150.

12. Lukes RJ, Butler JJ: The pathology and nomenclature of Hodgkin's disease. Cancer research 1966, 26(6):1063-1083.

13. Xiao C, Su ZL, Wu QL, Gao HY, Fang JC, Xia ZJ, Guan ZZ: Clinical and pathological reassessment of 493 cases of non-Hodgkin's lymphomas according to current WHO classification of lymphoid neoplasms. Zhonghua bing li xue za zhi Chinese journal of pathology 2005, 34(1):22-27.

14. Mwakigonja AR, Kaaya EE, Mgaya EM: Malignant lymphomas (ML) and HIV infection in Tanzania. J Exp Clin Cancer Res 2008, 27(1):9.

15. Aydin ZD, Barista I, Canpinar H, Sungur A, Tekuzman G: Gastric lymphomas in Turkey. Analysis of prognostic factors with special emphasis on flow cytometric DNA content. Cancer 2000, 89(1):12-20.

16. Czader M, Porwit A, Tani E, Ost A, Mazur J, Auer G: DNA image cytometry and the expression of proliferative markers (proliferating cell nuclear antigen and Ki67) in non-Hodgkin's lymphomas. Mod Pathol 1995, 8(1):51-58.

17. Castanos-Velez E, Heiden T, Lindvall C, Capello D, Sandlund A, Imreh S, Blennow E, Andersson LC, Gaidano G, Nordenskjold M, et al: Simian AIDSrelated lymphoma growth in severe combined immunodeficiency mice is independent of karyotypic abnormalities or Bcl-6 mutations. AIDS research and human retroviruses 2002, 18(5):383-390.

18. Biberfeld P, Christensson B, Andersson-Anvret M, Ernberg I, Lewensohn R, Ekman M, Johansson B, Tribukait B: An EBV-associated, Swedish case of Burkitt-type malignant lymphoma. Acta pathologica et microbiologica Scandinavica 1981, 89(6):417-424.

19. Pak F, Pyakural P, Kokhaei P, Kaaya E, Pourfathollah AA, Selivanova G, Biberfeld P: HHV-8/KSHV during the development of Kaposi's sarcoma: evaluation by polymerase chain reaction and immunohistochemistry. $J$ Cutan Pathol 2005, 32(1):21-27.

20. Katano H, Suda T, Morishita Y, Yamamoto K, Hoshino Y, Nakamura K, Tachikawa N, Sata T, Hamaguchi H, Iwamoto A, et al: Human herpesvirus 
8-associated solid lymphomas that occur in AIDS patients take anaplastic large cell morphology. Mod Pathol 2000, 13(1):77-85.

21. Carbone A, Gloghini A, Vaccher E, Cerri M, Gaidano G, Dalla-Favera R, Tirelli U: Kaposi's sarcoma-associated herpesvirus/human herpesvirus type 8-positive solid lymphomas: a tissue-based variant of primary effusion lymphoma. J Mol Diagn 2005, 7(1):17-27.

22. Newton R, Carpenter L, Casabonne D, Beral V, Babiker A, Darbyshire J, Weller I, Weiss R, Kwan A, Bourboulia D, et al: A prospective study of Kaposi's sarcoma-associated herpesvirus and Epstein-Barr virus in adults with human immunodeficiency virus-1. British journal of cancer 2006, 94(10):1504-1509.

23. Hans CP, Weisenburger DD, Greiner TC, Gascoyne RD, Delabie J, Ott G Muller-Hermelink HK, Campo E, Braziel RM, Jaffe ES, et al: Confirmation of the molecular classification of diffuse large B-cell lymphoma by immunohistochemistry using a tissue microarray. Blood 2004, 103(1):275-282.

24. Berglund $M$, Thunberg U, Amini RM, Book M, Roos G, Erlanson M, Linderoth J, Dictor M, Jerkeman M, Cavallin-Stahl E, et al: Evaluation of immunophenotype in diffuse large B-cell lymphoma and its impact on prognosis. Mod Pathol 2005, 18(8):1113-1120.

25. Muris JJ, Meijer CJ, Vos W, van Krieken JH, Jiwa NM, Ossenkoppele GJ, Oudejans JJ: Immunohistochemical profiling based on BCl-2, CD10 and MUM1 expression improves risk stratification in patients with primary nodal diffuse large B cell lymphoma. The Journal of pathology 2006, 208(5):714-723.

26. Dinand V, Malik A, Unni R, Arya LS, Pandey RM, Dawar R: Proliferative index and CD15 expression in pediatric classical Hodgkin lymphoma. Pediatric blood \& cancer 2008, 50(2):280-283.

27. Kim SJ, Kim BS, Choi CW, Choi J, Kim I, Lee YH, Kim JS: Ki-67 expression is predictive of prognosis in patients with stage $\mathrm{I} / \mathrm{Il}$ extranodal NK/T-cell lymphoma, nasal type. Ann Oncol 2007, 18(8):1382-1387.

28. Mwakigonja AR, Pak F, Pyakurel P, Mosha IJ, Urassa WK, Kaaya EE, Biberfeld P: Oral Kaposi's sarcoma in Tanzania: presentation, immunopathology and human herpesvirus-8 association. Oncology reports 2007, 17(6):1291-1299

29. Heiden T, Schumann J, Gohde W: Flow sorting of tumor cells for morphometric analysis, particularly of rare cells. Virchows Archiv 1991, 61(1):29-38.

30. Heiden T, Castro J, Graf BM, Tribukait B: Comparison of routine flow cytometric DNA analysis of fresh tissues in two laboratories: effects of differences in preparation methods and background models of cell cycle calculation. Cytometry 1998, 34(4):187-197.

31. Heiden T, Castanos-Velez E, Andersson LC, Biberfeld P: Combined analysis of DNA ploidy, proliferation, and apoptosis in paraffin-embedded cell material by flow cytometry. Laboratory investigation; a journal of technical methods and pathology 2000, 80(8):1207-1213.

32. Fanaian N, Cohen C, Waldrop S, Wang J, Shehata B: EBER: Automated In Situ Hybridization (ISH) vs. Manual ISH and Immunohistochemistry (IHC) for Detection of EBV in Pediatric Lymphoproliferative Disorders. Pediatr Dev Pathol 2008, 1.

33. Ott $\mathrm{G}$, Rosenwald A: Extranodal diffuse large B-cell lymphoma-an organotypic disease? Der Pathologe 2007, 28(1):29-35.

34. Yamauchi A, Fujita S, Ikeda J, Nakamichi I, Fukuhara S, Hino M, Kanakura Y Ogawa $\mathrm{H}$, Sugiyama $\mathrm{H}$, Kanamaru A, et al: Diffuse large B-cell lymphoma in the young in Japan: a study by the Osaka Lymphoma Study Group. American journal of hematology 2007, 82(10):893-897.

35. Lu JB, Li XQ, Zhang PH, Zhou XY, Zhang TM, Li XM, Zhu XZ: Nodal versus extranodal diffuse large B-cell lymphoma: comparison of clinicopathologic features, immunophenotype and prognosis. Zhonghua bing li xue za zhi Chinese journal of pathology 2007, 36(7):470-473.

36. Katsaounis P, Alexopoulou A, Dourakis SP, Smyrnidis A, Marinos L, Filiotou A, Archimandritis AJ: An extranodal NK/T cell lymphoma, nasal type: with specific immunophenotypic and genotypic features. International journal of hematology 2008, 88(2):202-205.

37. Kim TM, Lee SY, Jeon YK, Ryoo BY, Cho GJ, Hong YS, Kim HJ, Kim SY, Kim CS, Kim S, et al: Clinical heterogeneity of extranodal NK/T-cell lymphoma, nasal type: a national survey of the Korean Cancer Study Group. Ann Oncol 2008, 19(8):1477-84.

38. Martinez-Climent JA, Alizadeh AA, Segraves R, Blesa D, Rubio-Moscardo F, Albertson DG, Garcia-Conde J, Dyer MJ, Levy R, Pinkel D, et al: Transformation of follicular lymphoma to diffuse large cell lymphoma is associated with a heterogeneous set of DNA copy number and gene expression alterations. Blood 2003, 101(8):3109-3117.

39. Gupta AK, Meisner D, Talreja N, Smith R, Swerdlow SH: Classical nodular sclerosis Hodgkin lymphoma presenting with central nervous system disease. Southern medical journal 2007, 100(5):549-550.

40. Nitsu N, Nakamine H, Okamoto M, Tamaru Jl, Hirano M: A clinicopathological study of nm23-H1 expression in classical Hodgkin's lymphoma. Ann Oncol 2008, 19(11):1941-6.

41. Biggar RJ, Jaffe ES, Goedert JJ, Chaturvedi A, Pfeiffer R, Engels EA: Hodgkin lymphoma and immunodeficiency in persons with HIV/AIDS. Blood 2006, 108(12):3786-3791.

42. Killebrew D, Shiramizu B: Pathogenesis of HIV-associated non-Hodgkin lymphoma. Current HIV research 2004, 2(3):215-221.

43. Christensson B, Lindemalm C, Johansson B, Mellstedt $H$, Tribukait B, Biberfeld P: Flow cytometric DNA analysis: a prognostic tool in nonHodgkin's lymphoma. Leuk Res 1989, 13(4):307-314.

44. McDunn SH, Winter JN, Variakojis D, Rademaker AW, Von Roenn JH, Tallman MS, Gordon LI, Bauer KD: Human immunodeficiency virus-related lymphomas: a possible association between tumor proliferation, lack of ploidy anomalies, and immune deficiency. J Clin Oncol 1991, 9(8):1334-1340.

45. Krugmann J, Gschwendtner A, Mairinger T, Fend F: DNA ploidy in gastrointestinal B-cell lymphomas. An image analysis study of 43 cases. Anal Quant Cytol Histol 2003, 25(1):31-38.

46. Czader M, Porwit A, Ost A, Auer G: DNA content and expression of PCNA and $p 53$ in Hodgkin's disease and Hodgkin's-like B-cell lymphoma. Apmis 1994, 102(11):865-873.

47. Schmitt F, Tani E, Tribukait B, Skoog L: Assessment of cell proliferation by Ki-67 staining and flow cytometry in fine needle aspirates (FNAs) of reactive lymphadenitis and non-Hodgkin's lymphomas. Cytopathology 1999, 10(2):87-96.

48. Ioakim-Liossi A, Mikou P, Botsoli-Stergiou E, Petrakakou E, Athanassiadou P, Kordosis T, Panagiotakopoulos G, Karakitsos P: Primary effusion lymphoma. A case report. Acta cytologica 2004, 48(2):269-272.

\section{Pre-publication history}

The pre-publication history for this paper can be accessed here: http://www.biomedcentral.com/1471-2407/10/344/prepub

\section{doi:10.1186/1471-2407-10-344}

Cite this article as: Mwakigonja et al:: Tanzanian malignant lymphomas: WHO classification, presentation, ploidy, proliferation and HIV/EBV association. BMC Cancer 2010 10:344.

\section{Submit your next manuscript to BioMed Central and take full advantage of:}

- Convenient online submission

- Thorough peer review

- No space constraints or color figure charges

- Immediate publication on acceptance

- Inclusion in PubMed, CAS, Scopus and Google Scholar

- Research which is freely available for redistribution
C Biomed Central 